\title{
Talent Management: Three new Perceptions intended for managing and retaining Talent in Bangladesh
}

\author{
Md. Abul Mohaimen \\ Senior Lecturer, Faculty of Business, ASA University Bangladesh, Bangladesh
}

\begin{abstract}
This study aims at investigating the methods, importance, process, and present situation of managing talented employees in Corporations. The study revealed that having talented employees helps organizations to drive and be competitive but it is difficult to acquire such people. Thus, some innovative campaigns, for instance, global trainee and management cycle star programs have been created to motivate talented graduates to join the companies and to motivate existing talented employees to being more dedicated and engaged. In the recruitment of new employees, personality and interpersonal skills were more important than educational background because candidates were deemed to be proficient in specific areas, so, what a candidate must have is a personality matching the company's culture especially the characteristic of working as a good team member. In this study, we suggested some important steps and methods that can be applied in the organizations which are totally running and managing by the HR Department. Moreover, these methods and steps can become successful by managing low rate of star turnover which is quite sensitive case now a day.
\end{abstract}

Key words: Talent, Motivation, HR

JEL Classification Code: J24

\section{INTRODUCTION}

$\mathrm{T}$ The challenges facing profit and non-profit organizations are enormous. One of the most critical challenges for any organization is finding, recruiting, and retaining talented individuals. In the next decade, a diminishing pool of qualified candidates for key positions will make talent management even more essential to business success. Companies worldwide are having trouble filling positions. Forty percent of the employers surveyed reported problems in filling positions because of a lack of talent in their labor markets. Effective talent management becomes even more important with the forthcoming talent shortage as many experienced leaders approach retirement. In Bangladesh, fewer and fewer managers and professionals are ready to fill these leadership roles, and companies worldwide find themselves competing for a smaller pool of talent. Businesses must have the ability to identify the most talented individuals, provide them with the necessary training and experiences, and retain valuable employees long term economic benefits of talent management are demonstrated both at individual and corporate levels. At the corporate level, companies doing the best job of managing their talent also deliver better results for shareholders. An often-cited study shows that a standard deviation increase in high-performance talent management practices is associated with enormous economic return. However, managing talent cannot be completed within quarter or a year because it involves integrated planning and is not merely the responsibility of the human resources department but other factors are included in managing talent. Even though talent management is difficult and time consuming, it is very rewarding. Therefore, in our sense, the suggested methods and approaches of talent management would be advantageous to all organizations and practitioners who want to become a leader in this competitive arena.

\section{ObJectives of the study}

- To signify three diversified new ideas for managing talents in Bangladesh.

- To familiarize with the talent management methods as a functional toolkit.

\section{Literature ReVieW}

\subsection{Talent management:}

The term talent management is being used to describe sound and integrated human resources practices with the objectives of attracting and retaining the right individuals, for the right positions, at the right time. Organizations are run by people, and the talent of these people will determine the organizations' success, So, talent management is management's main priority. Today's businesses face increased global competition, shifting markets, and unforeseen events. No oneder they are finding it more difficult than ever to attract, develop, and retain the skilled workers they need Global talent management is also an organizational development 
solution that supports the HSBC vision to be the world's leading financial services company. To help accomplish this, HSBC implemented a global talent management process as one stream of a people strategy aimed at attracting, motivating, and retaining the very best. At HSBC global business strategy needed aligned people and talent management strategies. The first step was to identify the Senior Business Manager Talent pool, including both general managers and world-class specialists. The next steps were to expand the talent pool beyond a senior business manager level, implement development programs for future leaders according to levels of experience and seniority in an organization, and ensure the company had a customized solution to retain our talent through the employee value proposition (Gakovic \& Yardley, 2007).

Despite the great sums of money companies dedicate to talent management systems, many still struggle to fill key positions-limiting their potential for growth in the process. Virtually all human resource executives in a 2009 survey of 40 companies around the world said that their pipeline of high-potential employees was insufficient to fill strategic management roles. The survey revealed two primary reasons for this. First, the formal procedures for identifying and developing next-generation leaders have fallen out of sync with what companies need to grow or expand into new markets. To save money, for example, some firms have eliminated positions that would expose high-potential employees to a broad range of problems, thus sacrificing future development opportunities that would far outweigh any initial savings from the job cuts. Second, HR executives often have trouble keeping top leaders' attention on talent issues, despite those leaders' vigorous assertions that obtaining and keeping the best people is a major priority (Crane, 2001). A survey shows that executives do not know some of the most basic and most important facts about their companies' talent. Companies regularly mismanage talent development tasks. An employee value proposition can help management attract and retain the talent they need (Cliffe, 1998).

\subsection{Managing talent}

Increasingly, companies view the ability to manage talent effectively as a strategic priority. Yet, research finds that senior executives largely blame themselves and their business line managers for failing to give the issue enough time and attention. Moreover, executives who think that their companies' succession planning efforts are deficient don't, on balance, see talent-management processes and systems as a chief problem. Results of research suggest that obstacles preventing talent-management programs from delivering business value are all too human. Nearly half of the executives interviewed expressed concern that the senior leadership of their organizations doesn't align talent management strategies with business strategies.

However, (Heinen,2004) pointed out that talentmanagement processes include workforce planning, talent gap analysis, recruiting, staffing, education and development, retention, talent reviews, succession planning, and evaluation. To drive performance, deal with an increasingly rapid pace of change, and create sustainable success, a company must integrate and align these processes with its business strategies. By assessing available talent and placing the right people in their best roles, organizations can survive and thrive in today's increasingly competitive markets. Effective talent management becomes even more important with the forthcoming talent shortage as many experienced leaders approach retirement. Internationally, fewer managers and professionals are ready to fill these leadership roles, and companies worldwide find themselves competing for a smaller pool of talent. Businesses must have the ability to identify the most talented individuals, provide them with the necessary training and experiences, and retain valuable employee's long term (William,2000). To become successful, talent management require full participation of the organization's leaders. HR can't do the job alone. In short, more effective talent management is not about better HR processes; it's about a different mindset.

Today's top companies, however, know that a single department's potential effectiveness is limited; the key to a successful program lies with the cooperation of all departments, with all managers across the breadth of their operations. Every manager, no matter what level, plays a role in strengthening an organization's overall talent. For example, line managers who are accountable for getting work done are also accountable for developing the people they manage and are fundamental to making overall talent management work.

\subsection{Recruiting talent}

Identifying and attracting qualified candidates helps companies select people who not only possess the skills that are needed but also demonstrate the attitude, personality traits, and behavior that ensure organizational fit and promote commitment. After determining needs of an organization, high-performance companies develop a profile of the ideal candidate, aimed at hiring only the top 10 to 15 percent of the available talent (Hale, 1998). When a selection process begins, success factors identified for a job can provide a basis for an interviewing strategy that will assess the candidate's organizational fit. One of the strategies that can be used to determine a level of success is to incorporate behavioral-based questions that are designed to elicit examples from candidates about their work history and how they behaved in previous job situations. Another significan't strategy of ensuring the best fit is through competency-based management which can be described as the organization understanding its needs and who best fits with the organizations and then aiming to deliver the right outcomes by determining the valued behaviors. As a selection tool, this strategy helps with recruitment of employees who possess the requisite skills and behaviors to identify the long-term high potential employees (Hale, 1998). 


\subsection{Motivating talent}

Motivation can be regarded as the necessary drive or energy towards achievement of some goals (Analoui, 1999). Motivation can also be compared to an engine and steering wheel of a car because at the center of the concept of motivation are the energy, the direction, the drive or the factors influencing a person's behavior. Initiatives to improve job performance by increasing employee motivation may fail if there is a weak link between performance and employee efforts. Two types of motivation are commonly identified: intrinsic and extrinsic motivation. Intrinsic motivation is an internal driver, and extrinsic motivation is an environmental incentive, reward and challenges. Intrinsic motivation means a person engaged in some activity for its own sake because it is satisfying and no reward is expected. When someone has high intrinsic motivation, this person's feelings are closely related to how well he or she performs. To motivate, the talent the intrinsic motivation such as career planning and development is one of the effective factors.

From an HR perspective, career planning and development focused on ensuring an alignment of individual career planning and organization career management processes to achieve an optimal match of individual and organizational needs. One of the issues facing organizations is an ability to foster a workforce that creates organizational capabilities. Many human resource development academicians and practitioners (Abbasi \& Hollman, 2000) have suggested and used training and development as a means of accomplishing this critical task. A study conducted by Hale (1998) listed training and development as one of the top five most effective retention strategies. Employees are more committed to employers who are more committed to employees' long-term career development Dessler $(1999,2000)$. A rationale behind this thinking is that employees come to organizations with certain needs, desires, skills, and so forth and expect to find a work environment where they can utilize their abilities and satisfy many of their basic needs,. Therefore, with failing to provide for these basic needs, the commitment level tends to diminish and it increases the likelihood of the employees choosing to leave an organization.

Additionally, coaching is also one aspect of career development that can motivate talent effectively. Since the organization's success aligns in the talent knowledge of its people and for organizations to survive, they must develop current and future leaders (Blotch, 1995). Coaching has enormous benefits for both individuals and organizations. The potential implication for an organization that successfully employs an effective coaching strategy includes increased employee retention and satisfaction, enhanced motivation, morale, commitment and respect, improved organizational performance, communication and team effectiveness, and leveraged learning and creativity at lower costs.

\section{Methodology}

Qualitative research methodology was employed in order to achieve the objectives of the study. It is necessary to adopt an interpretive methodology to discover the details of the terms. In accordance with this argument, it is necessary to explore the subjective meaning of Talent Management with the ways it can be done. The human resources managers representing various companies had participated in the study. This work has done through census survey and the total population was 50 . The data accuracy was accurate and costly because all participants took part in this survey program. The sample ages ranged from 42 to 52 years. All the managers who participated played important strategic human resources and personnel development and management roles in their organizations. This was validated from a pilot study. All managers offered to co-operate fully with the study. Three important ways and methods of managing talent were finally articulated and decorated with diagrams so that it can be applied in a large scale near future.

\subsection{Data collection}

A semi-structured interview schedule was the main research instrument that used in data collection. Other instruments e.g. schedule of meetings, informal dialogues with participants' colleagues statements were used to triangulate data for its factual accuracy. All interviews were conducted in a private place of their choice e.g. at the participant's workplace or at a restaurant. A pilot study was carried out with a participant to attest the appropriateness of the questions in the interview. The main aim was to probe participants' experience in terms of the constructs, premises, presumptions, presuppositions and practices that drive what and how strategic decisions were made and implemented in their organizations. The questions covered participants' perceptions on strategic talent management contents, process and context and their evaluation in terms of talent management program impact on organizational activities and performance. However, before the interview began participants were informed of the tenets of strategic talent management to ensure that the experiences they described were related to issues of a talent management nature and not confined to day-to-day operational matters. Each interview lasted approximately 2 hours.

\section{FINDINGS}

Bangladesh is facing a lack of talented employees with the boom of fast moving consumer goods industries. Offering a higher salary is not the only important factor motivating talented employees working with an organization but other kinds of motivation such as career path, career development, and open communication are important factors as well. This is proved by the turnover rate of the company at merely $1 \%$ of total employees worldwide. The main reason for leaving a job is family condition, for instance, employees have to move to other countries with their husband or wife. So, it is difficult to find potential 
graduates to work with the company but to retain them is more difficult. The ex human resources director of Unilever told in the interview that that they try every way to keep talented and high potential employees with them because they know that by having this people the company can grow stably and sustainably in global market.

\subsection{Recruitment of suitable people}

Selection interview is the only method used in the recruitment of new employees. Potential applicants are invited to interview by a HR manager, and then a head of department or a team leader. However, HR People always looks at the experience of applicant's rather than their degree since experience is the most important factor that lead to success. Experience is also concentrated because they need experienced employees in some hi-tech projects.

\subsection{Talent management: Suggested Methods \\ Method 1:}

Organizations need to encourage "open communication" .Employees have the right to communicate what they need in order to increase productivity. Thus, talented employees can demonstrate their ability, skill, and knowledge as much as they can, and then their superior will be asked to evaluate performance of subordinates. This method is highly subjective and proper reasons for suggesting this method are:

Assessment centers are best to justify whether a new incumbent possess ample amount of talent or not?

Supervisors usually evaluate performance and conductivity of the subordinates.

Potential candidates are offered with a great training program.

Assessments centers send their reviews about the candidates further.

This method has a EEO (Equal Employment Opportunity) considerations.

Online performance appraisal can be possible.

The talent management process can begin with following stages:

(1) Superiors in every department can be asked to evaluate performance and productivity of their subordinate every six month;

(2) Superiors needed to provide total right to judge in sending potential subordinates to the training programs organized by both the group HR department and external training programs, However, employees can also apply for any training programs but HR department will select potential people with recommendation of head of department or team manager as the first priority.

(3) In case of people who are very talented ones can be sent to the assessment center with the external examiner which is a 3-day program.

(4) Management appraisal, however, need to be organize in every 2 years. Every manager can be asked to fill in evaluation form about working knowledge, technical, managerial, social, and leadership skills of his or her subordinates. While, subordinates were required to describe their strengths and weaknesses including experiences in that form.HR officers then evaluate information and select talented employees and young potential staff to take part in the process. Selected employees will be sent to the program called "management development circle star". Employees who take part in this program will be trained both on the job and off the job in order to prepare them to be promoted in managing positions on the next two years.

(5) As every position, each employee needs to get equal importance. However, employees can share ideas with the company by sending online recommendations and suggestions to HR department. In addition, every appraisal system needs to be conducted in online so that employees can express all things without any stress.

Online appraisal makes employees more comfortable than a paper-based one because they can do an appraisal anywhere and anytime they want.

(6) Finally a competitive salary scheme with a challenging job or responsibility can be given to talented or potential employees. Challenging responsibility can be offered to those who demonstrate good working performance with the recommendation of their supervisors. The salary level can be divided into different levels. Employees, who are assigned to work in additional challenging jobs, can be paid salary in higher level. 


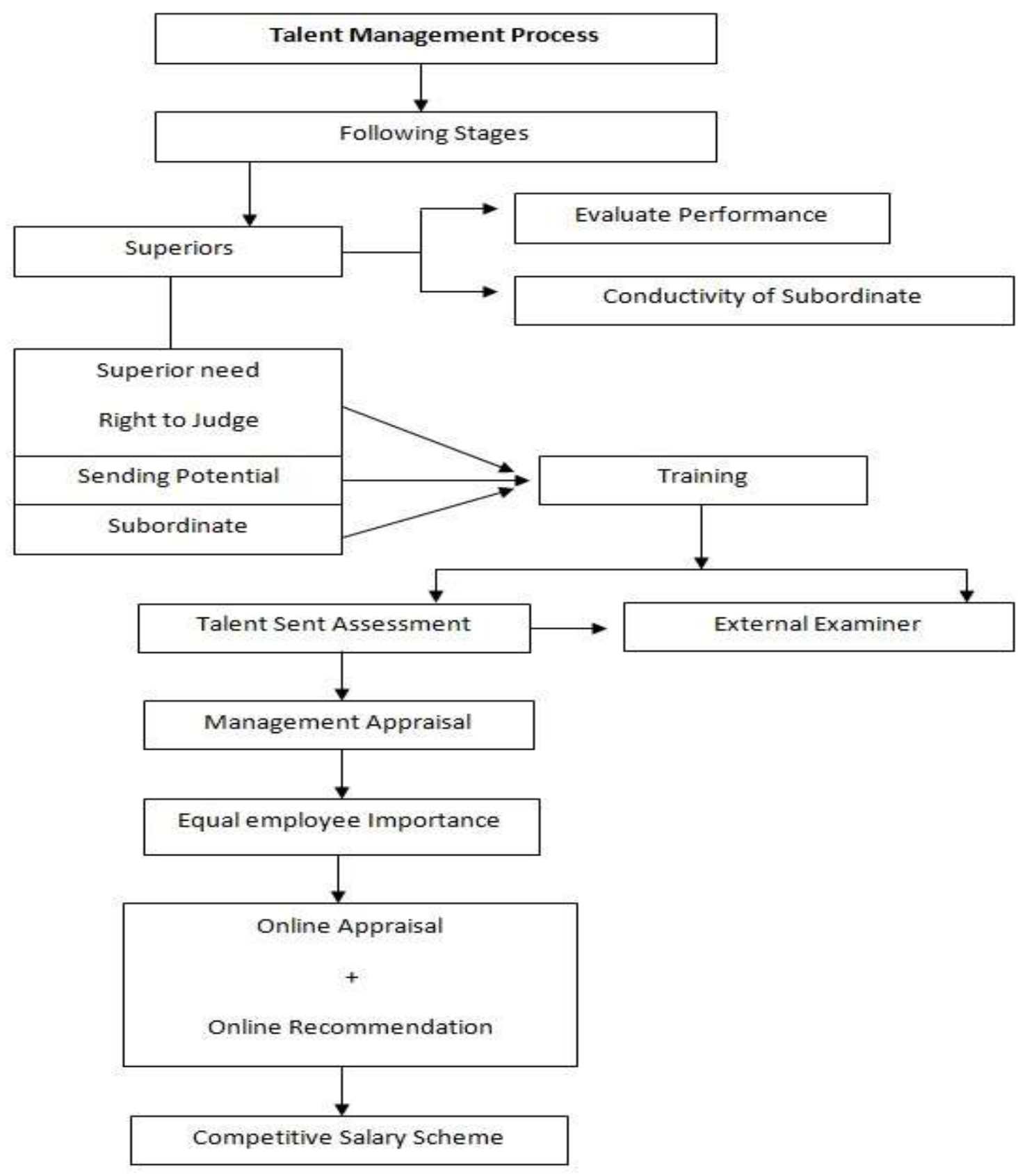

Figure: Suggested Method 1

\section{Method 2:}

Today many people apply for jobs but organizations really need those people who are proficient in their field of study and can work as a good team member.

1) Employees can be offered to join in a program but seats must be limited. Participation will be allowed according to recommendation of head of team or department. For example, British American Tobacco is offering potential students through campus recruitment by their "Battle of Mind" program.

2) In this method, Potential candidates can be invited to the interviews that are differently organized according to position applied. New employees will be trained and work in a department for three months, and then will be rotated to another. At the end of the third month, new employees and their heads of teams or departments need to be required to fill questionnaires. The boss of teams or department will be asked to evaluate new employees in 3 areas; (1) professional skill; (2) potential skill; and (3) personal skill. In addition, a mentor can be a key factor to help a new employee work effectively and smoothly as a team member.

3) After that, every employee needs to be promoted and succeeded in his or her career. It is difficult to motivate 
these talented people even though offering excessive higher salary than others in average. Thus, effective career path can be crucial motivating factor. In this case, a talented employee who performs a job that fit with his or her competence does not need to work in another position or department.

4) Training program designs, however, are always effective. All training programs must be matched with goal, vision, mission, and strategy of the company in case of both short and long term.

5) Finally, a structured questionnaire is required to prepare so that an employee can rank his or her ability, competence, attitude toward jobs, projects, department, and company including problems, and barriers at workplace. An employee can demonstrate all things that he or she needs to be done. While, a supervisor will also be required to evaluate an employee about professional, practical or technical, personal, leadership, and social skills. A supervisor or a department manager can be the key successful factor of performance evaluation and potential searching process because he or she realizes and sees an employee every day. A supervisor would be a person who knows an employee best. However, in order to avoid bias of performance evaluation, three to four supervisors including a human resource staff need to judge of an employee.

This method might work as an effective toolkit to find potential team or project talented leaders in the long run.

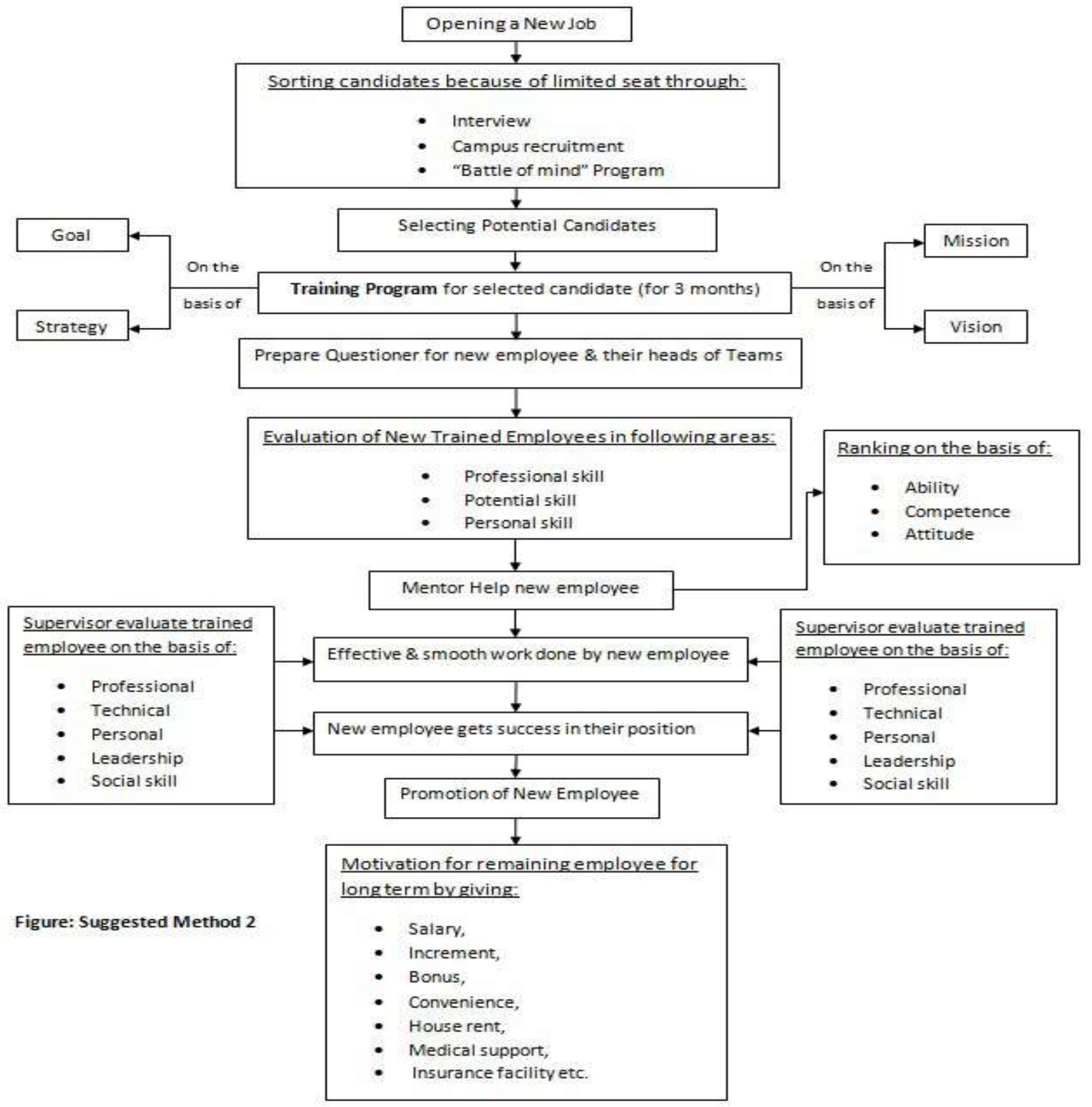

The proper reason for suggesting this method: 
Asian Business Review, Volume 3, Number 1/2013 (Issue 5)

ISSN 2304-2613 (Print); ISSN 2305-8730 (Online)

- Campus recruitment is less costly than any other recruitment process.

- This method works with unique mission, vision, strategy and goals from the very first insight.

- This method proposes a questionnaire for an employee as well as team where Delphi or Nominal group technique can be applied.

\section{Method 3:}

1) Online application is utilized as a recruiting instrument as it consumes less screening and working time.

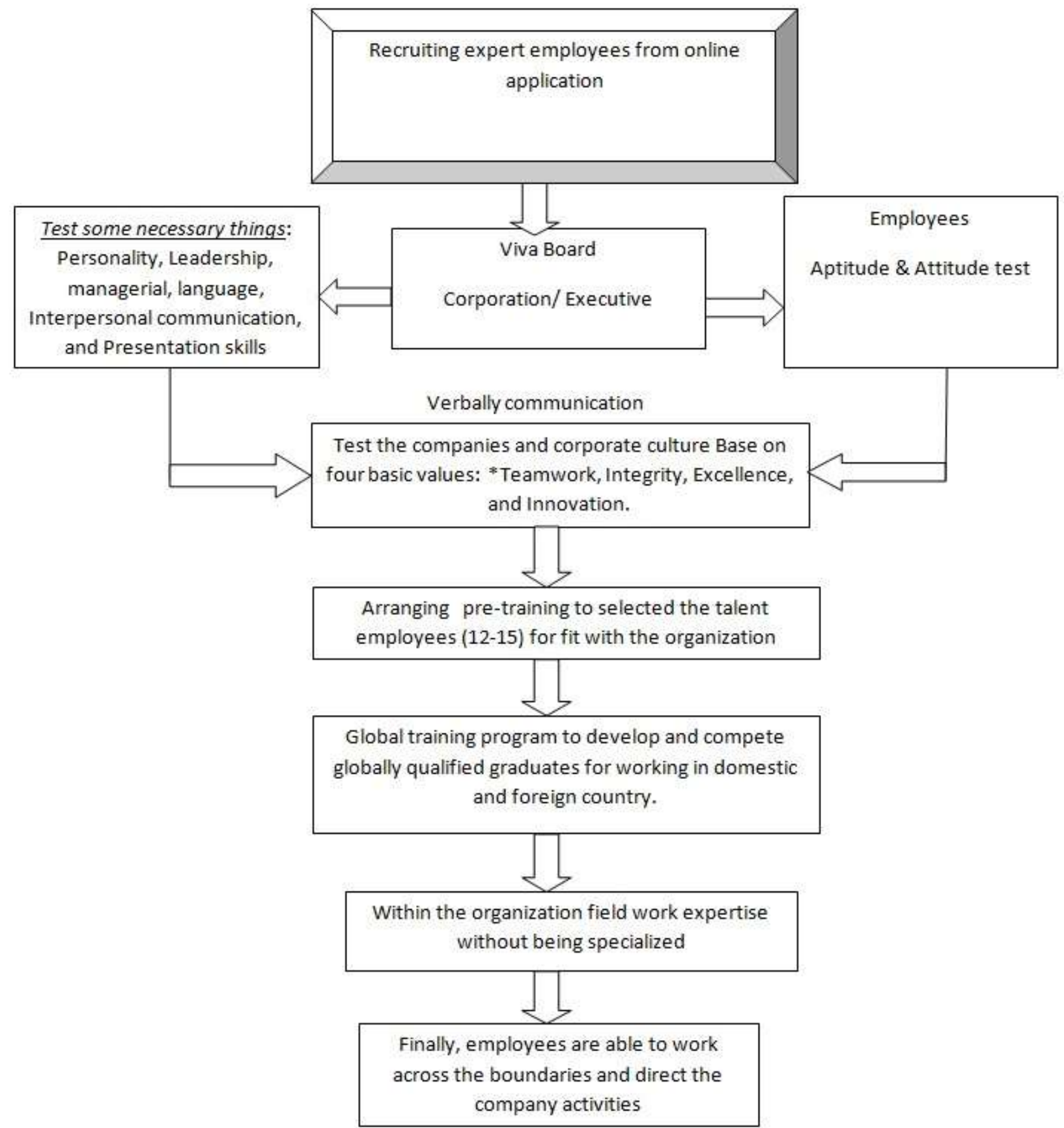

Figure: Suggested Method 3 
2) Then shortlisted need to conduct assessment tests such as aptitude and attitude tests as well as personality, leadership, managerial, language, interpersonal communication and presentation skills. The test covers all corporate needs because an organization would like those candidates who fit with the competencies and corporate culture that base on four basic values: (1) teamwork, (2) integrity, (3) excellence, and (4) innovation. The final decision will be judged by the management executives or appointed teams.

3) In this method, Pre-employment training can be a vital factor. Pre-training helps to acquire talented employees and finally arrange them with suitable jobs. 12-15 candidates can be anticipated and accepted into this program due to budget constrain.

4) In the mid career period a Global Trainee Program can be offered to develop qualified graduates to become excellent global managers. This program will enable those working in a multi-cultural environment that increasingly crosses geographical and organizational boundaries.

5) During the course of the Trainee Program trainees will learn more about the different opportunities. The program needs to manage in such a way so that it can enable trainees to gain insight within and beyond trainees' field of expertise without being specialized.

6) After that they can be used directly in company activities through their work on projects for different business units across the boundaries.

The proper reason for suggesting this method:

- Online application system can be applied here.

- A Viva Board can be formed in order to judge personality, leadership, aptitude test to judge the core knowledge of the employees.

- Teamwork is highly encouraged in this method which can ultimately helps to judge a person's introvertness.

- Pre-training and post-training both can be applied.

- Specialization got preference during the transitional phase.

- Successful employees can be capable enough to work across the boundaries and direct the company activities outside the territory.

\section{ReCOMmENDATIONS}

1) Talent management should be encouraged by an executive or managing board as one of urgent corporate agendas in every department it involved.

2) Obvious trainee program should be promoted in a recruitment of graduated talents.

3) Active Talent relationship management should be employed in a recruitment of graduated talents in various kinds of universities in order to acquire many choices. For example, British American Tobacco Bangladesh employs active talent relationship management in advertising, searching, and promoting its reputation among academic arena. A lot of talents from different fields and reputable

Copyright (C) 2013, Asian Business Consortium | ABR universities around the world are applied and it selects only the best ones.

4) Personality including attitude toward teamwork and a corporate should be strictly concentrated in an assessment process since those are talents but working in a multinational corporation or intercultural environment personality is more important factor than knowledge.

5) Success of a project does not merely depend on personal ability but personality and positive attitude toward a team as a member as well.

6) Obvious career path and development should be announced as one of major corporate polices in order to motivate talents and potential employees to contribute their resources for a company and their future.

7) Training and development program should be based on a corporate strategy in order to manage budget and employees efficiency and effectively.

8) Democracy in terms of open communication should be encouraged in order to decrease employees' stress and increase creativity. But employees should only be permitted to communicate with supervisors.

9) A feedback meeting after each stage with coach might reflect strengths and enables candidates to develop their individual plan.

10) To prepare talents in high tech projects, several topics such as Project Management, Conflict Management, Change Management, Communication and Teambuilding need to be given high priority.

\section{Conclusions}

Regarding the need of talented people, every company agrees that having talented employees helps them drive competitiveness but it is difficult to acquire this kind of people since the recruiting competition of talented people in the same industries is fierce, besides, the booming of some industries such as telecommunication, automotive, and financial industries is catching talented graduates and employees from them as well. Thus, some talented campaigns, for instance, global trainee program and management cycle star program need to be created in order to motivate talented graduates to join the companies and to motivate existing potential or talented employees for dedicating and engaging more with the firms. Tools such as online application, screening of applications, interview, invitation to assessment center, presentation of managerial and language skills, personality, attitude toward the companies, job, and society can do a remarkable job in this case. The main purpose of recruitment will be searching talented people who fit with the core competencies and corporate culture. All interviewed corporations pointed that personality and interpersonal skills are more important than educational background because they believe that every candidate is to be proficient in a specific science, so, what talented candidate must have is personality 
Asian Business Review, Volume 3, Number 1/2013 (Issue 5)

ISSN 2304-2613 (Print); ISSN 2305-8730 (Online)

that matches the companies' culture especially characteristic of working as a good team member. In the trainee program, candidates will be trained and assigned projects both individual and team projects as well as a mentor and a coach who advise about works, disciplines, rules, and corporate culture. During midlevel candidates will also needs to be rotated to international offices as intercultural skill is the important factor in leading competitiveness both individuals and corporate. Talented people who can work in intercultural environment are merely desired. This competency is always concentrated by all companies. For current employees, talented or high potential employees need to be searched by self assessment and supervisor assessment methods. Many companies offer the chance of speaking to employees that can be called "open communication" in terms of online and interpersonal communication. An annual discussion of supervisors and subordinates needs to be always encourage. HR should know the nature of subordinate best. While, subordinate also need to evaluate themselves about knowledge, technical, attitude toward job, leadership, social, and interpersonal skills as well as strengths and weaknesses. In addition, an online assessment is also employed as an evaluating instrument since it is easy and high confidential to assessors. To avoid bias of evaluation some companies will use a committee to judge the result. Another method is to use an autonomy project in order to search a potential leader is like a team will be formed but it should not assign a team leader. All members must have equal power and responsibility. A person who lead a team can obtain an ultimate goal should have good interpersonal and decision making skills, be motivate people, and systematic thinking. Many talented ones can be promoted to higher positions by using this method. Moreover, challenging responsibilities can be offered to talented and high potential employees because the challenges are desired and can always motivate talented employees continually. Due to the companies realize that high skill employees need to prove their competence constantly. All these approaches will lead successful motivation of talented employees by ensuring the low rate of turnover.

\section{REFERENCES}

Abbasi, S. \& Hollman, K. 2000, “Turnover: the real bottom-line”, Public Personnel Management, Vol. 23, No. 3, pp. 19 - 28.

Analoui, F. 1999, "What motivates senior manager? The case of Romania", Journal of Managerial Psychology, Vol. 15, No. 4, pp. 324 - 340.

Appleton, J. 2002, "Coaching process meets development needs of three types of leaders", The Right Communique, Vol. 7, No. 1 , pp. $3-5$.

Argyris, C. \& Schon, D. A. 1996, “Organisational Learning 2, Theory, Method and Practice", Addison-Wesley, New York.

Armstrong, M. 2001, "A Handbook of Human Resources Management Practice (8th ed.)", Milford: Kogan Page, US.

Blotch, S. 1995, "Coaching tomorrow's top managers", Executive Development, Vol. 8, No. 5, pp. 20 - 22.

Bolch, M. 2000, "The changing face of the workforce", Bill Communications, Vol. 37, No. 12, pp. 73 - 78.

Bowerman, J. \& Collins, G. 1999, "The coaching network: A program for individual and organizational development", Journal of Workplace Learning: Employee Counselling Today, Vol. 11, No. 8, pp. 291 - 297.

Cliffe, S. 1998, "Human resources: Winning the war for talent", Harvard Business Review, Vol. 76, No. 5, pp. 18 - 19.

Covey, S. R. 2000, "Teaching Organizations", Executive Excellence, Vol. 17, No. 3, pp. 20.

Crane, T. G. 2001, "The heart of coaching: using transformational coaching to create a high-performance culture". FTA Press, San Diego, CA.

Desseler, G. 1999, "How to earn your employees' commitment", Academy of Management Executive, Vol. 13, No. 2, pp. $58-67$.

Desseler, G. 2000, "Human Resource Management (8 ed.)", Prentice Hall, NJ.

Eccles, J. S. \& Wigfield, A 2002, "Motivational beliefs, values, and goals", Annual reviews of Psychology, Vol. 53, pp. $109-132$.

Frank, F. D. \& Taylor, C. R. 2004, "Talent Management: Trends that Will Shape the Future", HR. Human Resource Planning, Vol. 27, No. 1, pp. 33 - 41.

Gakovic, A. \& Yardley, K. 2007, “Global Talent Management at $H S B C$ ", Organization Development Journal, Vol. 25, No. 2 , pp. $201-205$.

Hale, J. 1998, "Strategic Rewards: Keeping your best talent from walking out the door", Compensation and Benefit Management, Vol.14, No. 3, pp. 39 - 50.

Heinen, J. S., \& O'Neill, C. (2004). “Managing talent to maximize performance". Employment Relations Today, Vol. 31, No. 2, pp. $67-82$.

Hunter, J. E., Schmidt, F. L. \& Judiesch, M. K. 1990, “Individual differences in output variability as a function of job complexity", Journal of Applied Psychology, Vol. 75, No. 1, pp. 28 - 42.

Sandler, S. 2003, "The changing face of talent management", HR Focus, Vol. 80, No. 5, pp.1-4.

Silverman, D. 2001, "Interpreting Qualitative Data, Methods of Analysing, Talk, Text and Interaction", SAGE, London.

Whitworth, L., Kimsey-House, H. \& Sandahl, P. 1998, "Co-active coaching: New skills for coaching people toward succes in work and life", Davies-Black Publishing, Palo Alto, CA.

Wiley, C. 1995, "What motivates employees according to over 40 years of motivation surveys", International Journal of Manpower, Vol. 18, No. 3, pp. $263-280$.

Williams, M. 2000, "The war for talent: Getting the best from the best", CIPD House, London.

Yin, R. K. 1994, "Case Study Research: Design and Methods (2nd ediion)", SAGE, Thousand Oaks, CA.

$$
--0--
$$

